extent or degree of coronary atheroma was found at necropsy in Glasgow men compared with London men, ${ }^{7}$ but mortality from ischaemic heart disease is much greater in Scotland, particularly around Glasgow, than in the south of England. ${ }^{8}$ Preliminary observations indicate that platelet aggregation to thrombin, collagen, and arachidonic acid is greater in farmers in the south-west of Scotland, where the mortality is high, than in farmers in the central east of Scotland, where the mortality is lower. ${ }^{9}$ Furthermore, the highest mortality from stroke in the UK is also in Scotland and particularly in the central-west and north-west regions. ${ }^{8}$

More data are needed to confirm or refute the longstanding views of an important association between a deficiency of EFAs and ischaemic heart disease. This may be mediated through prostaglandin-related thrombogenesis rather than the development of coronary atheroma. We now need to collect evidence to determine whether the addition of certain EFAs to the diet reduces indices of hypercoagulability in man. If so, such specific dietary supplementation should be tested formally to see if it is preventive in communities with a very high vascular mortality.

M F OLIVER

Department of Cardiology, Edinburgh EM3 9YW

'Sinclair, H M, Lancet, 1956, 1, 381.
' Bronte-Stewart, B, British Medical Bulletin, 1958 , 14,243

${ }^{3}$ Logan, R L, et al, Lancet, 1978, 1, 949. nsull, $W$, et al, fournal of Clinical Investigation, 1969 48, 1313.

Moncada, S, and

$1978,34,129$.
Nordoy, A, et al, Eurd

ordoy, A, et al, European fournal of Clinical Investiga tion, $1979,9,5$. 1, 229.

Renaud, S, personal communication, 1979.

SIR,-Before we rest on our laurels, satisfied that the decline in death rate from ischaemic heart disease in the USA, paralleled by changes in diet, at last gives us "overwhelming evidence for a nutritional aetiology of ischaemic heart disease"' (Dr J I Mann, 17 March, p 732), may I make a plea for a more careful temporal analysis of this association before we pronounce judgment upon it ?

I would be just as pleased as anyone else if this association were in fact causal, and if we were at last making inroads into the prevalence of this disease. In order to confirm this, however, and to avoid the trap of seeing only what we want to believe, we must demonstrate not just a parallel change in diet but the fact that the dietary change preceded the change in mortality. As we are dealing with a longterm degenerative process, it is naive to expect an instantaneous response to the modification of one of the many known riskfactors. If the dietary changes are indeed responsible for the decline in mortality, we would surely expect them to antedate the decline.

There has been a considerably accelerated decline in the mortality rate from ischaemic heart disease in the USA since the late 1960s, but what is equally significant is that the rate reached a plateau during the 1950 s. In other words, there was a definite deceleration at least a decade earlier. The alteration in causa factors contributing to this deceleration mus therefore have occurred at least in the early 1950 s, if not in the late 1940s. Does this coincide with the dietary changes? Perhaps the dietary influence is merely accelerating an already declining rate. If so, what is the cause of the original decline?

What I would like to see is an age- and sex-specific analysis of ischaemic heart disease rates in the USA since the 1940s, with cohort as well as cross-sectional analyses. When it is established just exactly which sectors of the population are contributing to the decline, and when this is tied to evidence of dietary changes in those sectors, perhaps we may then be a little more certain about the role of nutritional factors in this very important natural experiment.

DAvid St GeORGE

London E5 9EF

SIR,-Dr J I Mann (17 March, p 732) obviously has a touching confidence in the two trials of polyunsaturated fat (PUF) diets which made the flimsy cornerstones of the Royal College of Physicians-British Cardiac Society report. Mitchell disposes of the Finnish mental hospitals trial in the EEC report. Mann objects to secondary prevention trials because "the subjects are no longer young" but puts his faith in the Los Angeles Veterans trial on subjects aged from 55 to 88 Were they free of arterial disease ?

Secondary prevention trials cannot be brushed off and ignored. If a valid causal factor in a longlasting progressive disease is identified its reduction should logically retard further progression in identified patients and delay or reduce mortality. All published efforts to help by drug or dietary reduction of blood cholesterol have uniformly and convincingly failed. In addition to those quoted, a trial for eight years in Bavaria ${ }^{1}$ by Stocksmeier failed to improve prospects (and support from the food industry was reduced). A trial in patients under 60 in the University of New South Wales showed that those on PUF diets did much worse than those left on a free diet.

Primary prevention trials of cholesterol reduction by clofibrate have failed to produce convincing evidence of benefit. An interim report on a primary multifactorial dietetic (plus smoking and blood pressure control) trial in North Karelia ${ }^{3}$ has shown in the first three years an increased incidence of acute myocardial infarction from 14.9 to 18.4 per 1000 men and no change in incidence in the 30 to 64 age group. Even Dr Ruth M Kay (3 March, p 6283) admits that proof of benefit may be impossible. If we accept this why proceed with such massive propaganda which can benefit only commercial interests?

Since efforts at blood cholesterol reduction have failed interest is now shifting to high-density lipoprotein (HDL), alleged to be protective, and low-density lipoprotein (LDL), alleged to be damaging. The evidence quoted by Dr Kay that a PUF diet will favourably affect this ratio is equivocal.

Drs K G Taylor and D J Betteridge (17 February, p 485) believe that cholesterol feeding produce "atheroma," but experts like Benditt and Armstrong believe that the fatty lesion thus produced is a very poor model of the human disease. Impurities in cholesterol have vitiated many animal experiments. ${ }^{4}$ Purified cholesterol produces only xanthomatous lesions that never thrombose 5

Even in the rare homozygous form of familial hypercholesterolaemia the disease is quite different from the common form of coronary artery disease. It affects only the mouths of the coronary arteries, leaving the main vessels and their subepicardial branches unaffected. Dr Mann might consider this mportant difference in the cause of angina.

The Belgian report proved nothing, as the mortality in 1947 in North Belgium was already lower than in South Belgium before preference for margarine occurred. Furthermore comparisons are hardly acceptable between two different ethnic groups.

The Blumgart report ${ }^{6}$ on induced myxoedema is criticised by Mann and Dr P B S Fowler (10 March, p 681). The method of cholesterol estimation at that time gave much lower values. The upper limit was taken as $230 \mathrm{mg}$ (today $300 \mathrm{mg}$ ). All patients showed a rise in cholesterol, and five out of eight reached concentrations of 338 to 524, which were very gross. After many years of this induced hypercholesterolaemia there were no coronary occlusions. I give priority to Blumgart for this most meaningful result of a planned therapeutic experiment which does not require statistics to prove its validity.

We must not confuse correlations or risk factors with causes. The Framingham study showed that $82 \%$ of those with all four risk factors (cholesterol, smoking, blood pressure, and sedentary lives) were still alive after 10 years, so the predictive value of any one risk factor is very limited. Cigarette smoking indeed has the strongest correlation and demonstrations of damage to the vascular endothelium by cigarette smoke encourages recognition of this hazard.

Norum's poll of 214 doctors (only a limited number of whom were critical scientists) was answered by $85 \%$. As $92 \%$ of those who answered were already following the diet the result was only an indication of wishful thinking.

I agree that death rates from coronary heart disease in different countries are difficult to compare. That France has been under-recording its deaths from this cause by more than half ${ }^{7}$ owing to different diagnostic habits is a salutary reminder of the fallibility of these figures. But a rise from the baseline may be meaningful in an individual population (for example, Sweden). It is certain that the high PUF diet of Israelis does not prevent a high incidence of the disease.

Dr J R Vane's approach (17 February, p 484) gives a rational twist to the story. Rather than concentrate on cholesterol reduction there are hopes that certain fatty acids may be precursors of antithrombotic substances, and this is to be pursued. It might even be relevant to plaque formation if Duguid's work ${ }^{5}$ is right. The real cause of coronary obstruction is thrombosis.

We need a fresh approach to the problem at scientific level and should avoid further public speculation and confusion by repeated propaganda through the media until we have clarified our own professional minds and shaken off what most critical doctors are likely to regard as an untenable hypothesis of causation.

London, NW11 7AA

J M MCMICHAEL

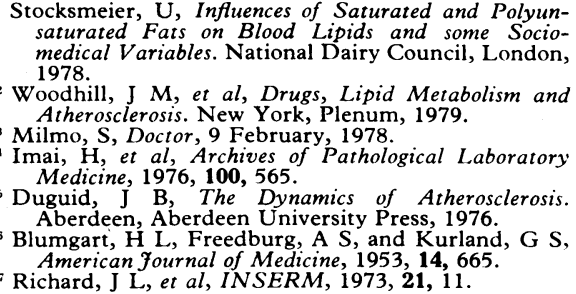

\section{Return to work after coronary artery} surgery for angina

SIR,-Drs P G F Nixon and N G Weinstock should not be astonished (27 January, p 265) at the successful results published by $\mathrm{Mr} \mathrm{J}$ Wallwork and others (16 December, p 1680). Not only do these results accord remarkably with other transatlantic experience but also with results in England.

From the United States, Cannon ${ }^{1}$ reports that $63 \%$ of 375 survivors of saphenous vein bypass grafting for angina were working postoperatively, while a further $16 \%$ were angina free but not working. Similarly, Rimm² reports that $83 \%$ of 893 men (mean age 52.3 years) returned to employment.

At the meeting of the Society of Thoracic 